\title{
亚热带不同树种凋落叶分解对氮添加的响应
}

\author{
陈思路 ${ }^{1,2}$ 蔡劲松 ${ }^{4}$ 林成芳 ${ }^{1,2,3 *}$ 宋豪威 ${ }^{1,2}$ 杨玉盛 $1,2,3$
}

${ }^{1}$ 福建师范大学地理科学学院, 福州 350007 ; ${ }^{2}$ 湿润亚热带山地生态国家重点实验室培育基地, 福州 $350007 ;{ }^{3}$ 福建三明森林生态系统与全球变化研究 站, 福建三明 $365000 ;{ }^{4}$ 福建省三明市郊国有林场, 福建三明 365000

摘 要 为探究不同质量调落物对氮 $(\mathrm{N})$ 沉降的响应, 该研究采用尼龙网袋分解法, 在亚热带福建三明格氏栲(Castanopsis kawakamii)自然保护区的米槠(Castanopsis carlesii)天然林, 选取4种本区常见的具有不同初始化学性质的树种调落叶进行模 拟 $\mathrm{N}$ 沉降(N添加)分解实验(施 $\mathrm{N}$ 水平为对照 0 和 $50 \mathrm{~kg} \cdot \mathrm{hm}^{-2} \cdot \mathrm{a}^{-1}$ )。研究结果表明: 在 2 年的分解期内, 对照处理的各树种调落叶的 分解速率依次为观光木(Michelia odora, $\left.0.557 \mathrm{a}^{-1}\right)$ 、米楮 $\left(0.440 \mathrm{a}^{-1}\right)$ 、台湾相思(Acacia confusa, $\left.0.357 \mathrm{a}^{-1}\right)$ 、杉木(Cunninghamia lanceolata, $\left.0.354 \mathrm{a}^{-1}\right)$; $\mathrm{N}$ 添加处理调落叶分解速率依次为观光木 $\left(0.447 \mathrm{a}^{-1}\right)$ 、米楮 $\left(0.354 \mathrm{a}^{-1}\right) 、$ 杉木 $\left(0.291 \mathrm{a}^{-1}\right)$ 、台湾相思 $(0.230$ $\mathrm{a}^{-1}$ ), 除杉木凋落叶外, N添加显著降低了其他 3 种凋落叶分解速率。 $\mathrm{N}$ 添加不仅使 4 种树木凋落叶分解过程中的 $\mathrm{N}$ 释放减慢, 同 时还抑制调落叶化学组成中木质素和纤维素的降解; N添加在调落叶分解过程中总体上提高 $\beta$-葡萄糖苷酶 $(\beta \mathrm{G})$ 和酸性磷酸酶 活性, 对纤维素水解酶的活性影响不一致, 而降低 $\beta-\mathrm{N}$-乙酰氨基葡萄糖苷酶活性和酚氧化酶活性。调落叶分解速率与调落叶 中的碳获取酶 $(\beta \mathrm{G})$ 活性以及其化学组分中的可萃取物含量极显著正相关, 与初始碳浓度、纤维素和木质素含量极显著负相关, 与初始 $\mathrm{N}$ 含量没有显著相关性。调落物类型和 $\mathrm{N}$ 添加的交互作用虽未影响干质量损失速率, 但对木质素和纤维素的降解具有 显著效应。综上所述, 化学组分比初始 $\mathrm{N}$ 含量能更好地预测调落叶分解速率, 而 $\mathrm{N}$ 添加主要通过抑制分解木质素的氧化酶(如 $\mathrm{PHO})$ 来降低调落叶分解速率。

关键词 调落叶分解; 氮沉降; 酶活性; 亚热带森林

陈思路, 蔡劲松, 林成芳, 宋豪威, 杨玉盛 (2020). 亚热带不同树种调落叶分解对氮添加的响应. 植物生态学报, 44, 214-227. DOI: 10.17521/cjpe.2019.0299

\section{Response of leaf litter decomposition of different tree species to nitrogen addition in a sub- tropical forest}

CHEN Si-Lu ${ }^{1,2}$, CAI Jin-Song ${ }^{4}$, LIN Cheng-Fang ${ }^{1,2,3^{*}}$, SONG Hao-Wei ${ }^{1,2}$, and YANG Yu-Sheng ${ }^{1,2,3}$

${ }^{1}$ School of Geographical Sciences, Fujian Normal University, Fuzhou 350007, China; ${ }^{2}$ State Key Laboratory of Humid Subtropical Mountain Ecology, Fuzhou, 350007, China; ${ }^{3}$ Sanming Research Station of Forest Ecosystem and Global Change, Sanming, Fujian 365000, China; and ${ }^{4}$ State-owned Forest Farm in the Suburbs of Sanming, Fujian Province, Sanming, Fujian 365000, China

\section{Abstract}

Aims Litter decomposition plays a vital role in nutrient recycling of forest ecosystems. The decomposition rate of leaves can vary among tree species with different substrate quality and environmental conditions, such as the supply of exogenous nitrogen $(\mathrm{N})$. However, the effects of exogenous $\mathrm{N}$ on leaf litter decomposition of different tree species in subtropical forests with high nitrogen deposition background remain poorly understood. Thus this study was designed to address the effect of $\mathrm{N}$ addition on litter decomposition of different tree species in a subtropical forest ecosystem.

Methods Leaf litters of four common tree species with contrasting substrate quality were collected and decomposed in fertilized $\left(50 \mathrm{~kg} \mathrm{~N} \cdot \mathrm{hm}^{-2} \cdot \mathrm{a}^{-1}\right)$ and control $\left(0 \mathrm{~kg} \mathrm{~N} \cdot \mathrm{hm}^{-2} \cdot \mathrm{a}^{-1}\right)$ plots for up to two years by using the nylon bag method, in Sanming Castanopsis kawakamii nature reserve of Fujian Province.

Important findings The litter decomposition rate in control plots ranked as follows: Michelia odora $\left(0.557 \mathrm{a}^{-1}\right)$, Castanopsis carlesii $\left(0.440 \mathrm{a}^{-1}\right)$, Acacia confusa $\left(0.357 \mathrm{a}^{-1}\right)$, Cunninghamia lanceolata $\left(0.354 \mathrm{a}^{-1}\right)$, while the decomposition rate in $\mathrm{N}$ addition plots ranked as follows: Michelia odora $\left(0.447 \mathrm{a}^{-1}\right)$, Castanopsis carlesii $\left(0.354 \mathrm{a}^{-1}\right)$, Cunninghamia lanceolata $\left(0.291 \mathrm{a}^{-1}\right)$, Acacia confusa $\left(0.230 \mathrm{a}^{-1}\right)$. Overall, $\mathrm{N}$ addition significantly

收稿日期Received: 2019-11-04 接受日期Accepted: 2020-02-06

基金项目：国家自然科学基金(31770663)和福建省自然科学基金(2018J01718)。Supported by the National Natural Science Foundation of China (31770663), and the Natural Science Foundation of Fujian (2018J01718).

* 通信作者Corresponding author (tonylcf99@163.com) 
increased the litter mass remaining of Michelia odora, Acacia confusa and Castanopsis carlesii, but not Cunninghamia lanceolata. $\mathrm{N}$ addition not only slowed down the release of $\mathrm{N}$, but also retarded the degradation of lignin and cellulose in the decomposition process. Moreover, $\mathrm{N}$ addition increased the activities of $\beta$-glucosidase $(\beta G)$ and acid phosphatase, had species-specific effects on the activity of cellulose hydrolase, and decreased the activity of $\beta$-N-acetylglucosaminidase and phenoloxidase (PHO). The litter mass loss rate was positively correlated with the activities of carbon acquiring enzyme $(\beta G)$ in litter layer and the extractives, negatively correlated with carbon concentration, cellulose and lignin, but did not correlate significantly with the initial $\mathrm{N}$ concentration. Further analysis found an interactive effect of litter type and $\mathrm{N}$ addition on the degradation of cellulose and lignin, but not on dry mass loss. Overall, our results demonstrated that litter chemical components may be better parameters to predict the decomposition rate of leaf litters than the initial nutrient concentrations, and $\mathrm{N}$ addition could decrease leaf litter decomposition by inhibiting oxidase (e.g. PHO). We call for further experiments to involve more species and longer time for revealing the response of leaf litter decomposition and its extracellular enzyme activity to $\mathrm{N}$ addition.

Key words leaf litter decomposition; nitrogen deposition; enzyme activities; subtropical forest

Chen SL, Cai JS, Lin CF, Song HW, Yang YS (2020). Response of leaf litter decomposition of different tree species to nitrogen addition in a subtropical forest. Chinese Journal of Plant Ecology, 44, 214-227. DOI: 10.17521/cjpe.2019.0299

由于化石燃料的燃烧和氮(N)肥的大量生产与 使用, 人类活动向大气排放越来越多的含 $\mathrm{N}$ 化合物, 导致大气N沉降增加。排放到大气中的N, 从1860年 的34 $\mathrm{Tg} \cdot \mathrm{a}^{-1}$ 增加到1995年的 $100 \mathrm{Tg} \cdot \mathrm{a}^{-1}$, 预计到2050 年会增加到 $200 \mathrm{Tg} \cdot \mathrm{a}^{-1}$ (Galloway et al., 2008)。 $\mathrm{N}$ 沉 降可以提高土壤N有效性, 影响微生物群落结构和 活性(郑裕雄等, 2018), 进而影响调落物分解(Fang et al., 2007; Cotrufo et al., 2013), 并通过改变土壤有 机质的合成与分解, 影响陆地生态系统碳 $(\mathrm{C}) 、 \mathrm{~N}$ 循 环(Vitousek et al., 1997; Galloway et al., 2008)。以往 关于 $\mathrm{N}$ 沉降的研究大多集中在土壤 $\mathrm{N}$ 相对缺乏的温 带和北方森林, 而近年来开始关注热带、亚热带地 区(Zhou et al., 2017; Yu et al., 2018)。我国是全球三 大严重N沉降地区之一, 尤其以东部地区最为严重 (Galloway et al., 2008), 大气N沉降可能严重影响我 国亚热带森林生态系统的养分循环。

森林调落物分解是森林生态系统物质循环和能 量转换的主要途径, 是养分循环的关键环节, 它提 供生态系统中植物生长所需的有效 $\mathrm{N}$ 和其他元素 (Wieder et al., 2009)。过去的研究表明在全球和区域 尺度上, 气候是调控调落物分解的首要因素(Aerts, 1997; Zhang \& Wang, 2015), 而在局域尺度, 调落物 分解速率不仅与底物的化学组分, 如易分解的水溶 性 C组分(可萃取物), 难分解的木质素(酸不溶性物 质)含量, 以及初始养分 (如 $\mathrm{N}$ 、磷 $(\mathrm{P})$ ) 含量等有很好 的相关关系(Allison \& Vitousek, 2004; Cornwell et al., 2008; 李雪峰等, 2008; 杨林等, 2015), 还与 分解环境中N (外源)的供应有关(Vivanco \& Austin,
2011; 涂利华等, 2012; 林成芳等, 2017; Zheng et al., 2017)。然而, 不同初始化学性质和不同外源N供应 如何影响调落物分解这一基本生态过程的机制仍不 清楚(Hobbie et al., 2012)。因此, 在高N沉降背景下, 有必要对高生物多样性的热带和亚热带地区的调落 物分解进行 $\mathrm{N}$ 添加的深入研究。

微生物是调落物的最终分解者, 调落物本身的 性质和周围土壤环境的长期相互作用影响微生物群 落的结构和分解功能(Keiser et al., 2014; van Huysen et al., 2016; Palozzi \& Lindo, 2018; Yan et al., 2018)。 近年来很多研究表明, 胞外酶活性的动态能较好地 解释调落物分解的变化 (Waring, 2013; Dong et al., 2019), 如N添加改变了木质素降解酶(酚氧化酶)以 及其他水解酶的活性, 从而改变了调落物的分解速 率(Saiya-Cork et al., 2002; Sinsabaugh et al., 2005; Stursova et al., 2006)。测定酶活性能够直接跟踪微 生物群落对调落物性质和环境变量的功能响应 (Carreiro et al., 2000), 但由于植物-调落物-微生物 交互作用具有潜在的复杂性, 酶活性会对调落物 性质和外源 $\mathrm{N}$ 输入的改变做出何种响应, 目前尚不 清楚。

位于亚热带的福建三明拥有面积广大的常绿阔 叶林, 树种多样性丰富, 米槠(Castanopsis carlesii)、 观光木 (Michelia odora) 等皆为该区森林的常见树 种。近几十年来, 为满足对木材等林产品的需求, 大 量的天然林被砍伐代之以生长速度快的人工林, 如 杉木(Cunninghamia lanceolata) 林等(Yang et al., 2009)。台湾相思(Acacia confusa) 耐干旱贫疹、生长 
快, 有根瘤菌能固 $\mathrm{N}$, 也常被选为改良立地的人工 造林树种(陈志锋等, 2016)。本研究选取以上 4 个常 见树种调落叶测定其初始化学性质(如初始N、P浓 度等), 结合外源 $\mathrm{N}$ 添加试验, 观测分解过程中 $\mathrm{N}$ 的 释放, 化学组分以及胞外酶的变化, 探讨初始化学 性质和 N有效性与调落物分解的关系。研究结果对 在高 $\mathrm{N}$ 沉降背景下, 深入认识亚热带森林生态系统 的 $\mathrm{C} 、 \mathrm{~N}$ 循环机制有一定的意义。

\section{1 材料和方法}

\section{1 研究区概况}

试验地设在福建省三明格氏栲 (Castanopsis kawakamii $)$ 自然保护区 $\left(26.17^{\circ} \mathrm{N}, 117.45^{\circ} \mathrm{E}\right)$ 内, 该研 究区平均海拔 $300 \mathrm{~m}$, 地形以低山丘陵为主。属亚热带 季风气候, 多年平均气温 $19.1{ }^{\circ} \mathrm{C}$, 年降水量 $1749 \mathrm{~mm}$ 。 土壤主要为花岗岩或砂岩发育的酸性红壤, 土层厚 度一般超过 $1 \mathrm{~m}$ 。实验区为近 200 年无人干扰的米槠 天然林, 样地海拔为 $315 \mathrm{~m}$, 坡向 $\mathrm{NE} 25^{\circ}$, 坡度 $35^{\circ}$, 土壤为黑云母花岗岩发育的红壤。优势种为米槠, 其他树种有木荷(Schima superba)、格氏栲、马尾松 (Pinus massoniana)、虎皮楠(Daphnipnhyllum oldhamii)、 桂北木姜子(Litsea subcoriacea)、杜英(Elaeocarpus decipiens)、毛冬青(Ilex pubescens)等。群落分层明
显, 可划分为乔木层、灌木层和草本层 3 个层次。林 下地被层较厚, 并且散布有枯立木、倒木和死树枝 杆等, 枯枝落叶厚度为 5-8 cm (林伟盛等, 2013)。林 分详细概况参见表1 (王家骏等, 2014)。

\section{2 样品采集}

2011年3-5月, 在福建三明格式栲保护区内的 台湾相思林、观光木林、米槠林和杉木林内设置调 落物收集框，收集新鲜调落物带回室内风干备用。 将 4 种风干的调落叶分别混合均匀, 各称取 $(10 \pm$ $0.05) \mathrm{g}$, 装入大小为 $20 \mathrm{~cm} \times 20 \mathrm{~cm}$ 、网孔为 $1 \mathrm{~mm} \times$ $1 \mathrm{~mm}$ 的尼龙网袋中, 每种调落叶各随机取 3 袋, 测 定其初始化学性质(表2)。

\section{3 实验设计}

在米楮天然林内随机选取 2 个 $3 \mathrm{~m} \times 3 \mathrm{~m}$ 的样方 放置凋落物分解袋, 设置施 $\mathrm{N}\left(+\mathrm{N}, 50 \mathrm{~kg} \cdot \mathrm{hm}^{-2} \cdot \mathrm{a}^{-1}\right)$ 和对照 $\left(\mathrm{CT}, 0 \mathrm{~kg} \cdot \mathrm{hm}^{-2} \cdot \mathrm{a}^{-1}\right)$ 处理, 每个处理 6 个重复。 不同样方具有相同的土壤类型、近似的海拔和坡度, 样方之间设 $5 \mathrm{~m}$ 的缓冲带。从 2011 年 8 月开始进行施 $\mathrm{N}$ 处理, 先清除地表调落物层, 将调落物分解袋置 于地表固定, 然后将处理所需的 $\mathrm{NH}_{4} \mathrm{NO}_{3}$ 溶解于 $1 \mathrm{~L}$ 的水中, 在每季度末用喷雾器均匀喷酒在网袋表面, 每年喷酒 4 次, 实验为期 2 年, 共喷酒 8 次。对照处理 则喷酒相同体积的水。

表1 亚热带米槠天然林群落特征与土壤表层 $(0-10 \mathrm{~cm})$ 理化性质

Table 1 Community characteristics and topsoil $(0-10 \mathrm{~cm})$ physiochemical properties of a subtropical Castanopsis carlesii natural forest

\begin{tabular}{|c|c|c|c|c|c|c|c|}
\hline \multicolumn{4}{|c|}{ 林分特征 Forest characteristics } & \multicolumn{4}{|c|}{ 土壤理化性质 Soil physiochemical properties } \\
\hline $\begin{array}{c}\text { 林分密度 } \\
\text { Stand density } \\
\left(\text { 株· } \mathrm{hm}^{-2}\right)\end{array}$ & $\begin{array}{c}\text { 郁闭度 } \\
\text { Canopy density }\end{array}$ & $\begin{array}{c}\text { 平均树高 } \\
\text { Mean tree height } \\
\text { (m) }\end{array}$ & $\begin{array}{c}\text { 平均胸径 } \\
\text { Mean } D B H \\
(\mathrm{~cm})\end{array}$ & $\begin{array}{c}\text { 容重 } \\
\text { Bulk density } \\
\left(\mathrm{g} \cdot \mathrm{cm}^{-3}\right)\end{array}$ & $\begin{array}{c}\text { 全C } \\
\text { Total carbon } \\
(\%)\end{array}$ & $\begin{array}{c}\text { 全N } \\
\text { Total nitrogen } \\
(\%)\end{array}$ & $\begin{array}{c}\text { 全P } \\
\text { Total phosphorus } \\
(\%)\end{array}$ \\
\hline 1955 & 0.89 & 11.9 & 20 & 1.12 & 2.45 & 0.186 & 0.0217 \\
\hline
\end{tabular}

$D B H$, diameter at breast height.

表2 亚热带森林不同调落叶初始化学性质(平均值土标准偏差, $n=3$ )

Table 2 Initial chemical properties of leaf litter in a subtropical forest (mean $\pm S D, n=3$ )

\begin{tabular}{|c|c|c|c|c|c|c|c|c|c|c|}
\hline 树种 Species & $\mathrm{C}\left(\mathrm{g} \cdot \mathrm{kg}^{-1}\right)$ & $\mathrm{N}\left(\mathrm{g} \cdot \mathrm{kg}^{-1}\right)$ & $\mathrm{P}\left(\mathrm{g} \cdot \mathrm{kg}^{-1}\right)$ & $\begin{array}{c}\text { 可萃取物 } \\
\text { Extractive (\%) }\end{array}$ & $\begin{array}{c}\text { 纤维素 } \\
\text { Cellulose (\%) }\end{array}$ & $\begin{array}{c}\text { 木质素 } \\
\text { Lignin (\%) }\end{array}$ & $\mathrm{C}: \mathrm{N}$ & $\mathrm{C}: \mathrm{P}$ & $\begin{array}{l}\text { 木质素:N } \\
\text { Lignin:N }\end{array}$ & $\begin{array}{l}\text { 木质素:P } \\
\text { Lignin:P }\end{array}$ \\
\hline $\begin{array}{l}\text { 米槠 } \\
\text { Castanopsis } \\
\text { carlesii }\end{array}$ & $486.44 \pm 2.15$ & $14.22 \pm 0.19$ & $0.34 \pm 0.03$ & $55.50 \pm 1.58$ & $24.50 \pm 1.07$ & $20.00 \pm 1.02$ & $34.21 \pm 2.13$ & $1158.20 \pm 0.78$ & $1.41 \pm 0.05$ & $47.62 \pm 1.56$ \\
\hline $\begin{array}{l}\text { 杉木 } \\
\text { Cunninghamia } \\
\text { lanceolata }\end{array}$ & $525.05 \pm 2.39$ & $16.03 \pm 0.16$ & $0.79 \pm 0.10$ & $51.40 \pm 0.95$ & $24.30 \pm 1.02$ & $24.30 \pm 0.85$ & $32.75 \pm 0.95$ & $664.62 \pm 0.50$ & $1.52 \pm 0.05$ & $30.76 \pm 5.46$ \\
\hline $\begin{array}{l}\text { 观光木 } \\
\text { Michelia } \\
\text { odora }\end{array}$ & $390.24 \pm 1.68$ & $24.26 \pm 0.12$ & $0.92 \pm 0.05$ & $55.20 \pm 0.97$ & $25.50 \pm 0.95$ & $19.30 \pm 1.16$ & $16.10 \pm 0.26$ & $424.45 \pm 0.36$ & $0.80 \pm 0.28$ & $20.98 \pm 2.15$ \\
\hline $\begin{array}{l}\text { 台湾相思 } \\
\text { Acacia } \\
\text { confusa }\end{array}$ & $501.37 \pm 2.81$ & $27.61 \pm 0.36$ & $0.56 \pm 0.02$ & $51.10 \pm 1.87$ & $26.60 \pm 0.45$ & $22.30 \pm 0.81$ & $18.14 \pm 0.09$ & $894.69 \pm 0.52$ & $0.81 \pm 0.35$ & $39.82 \pm 0.97$ \\
\hline
\end{tabular}




\section{4 凋落物样品收集与处理}

在调落物袋放置后的第3、6、9、12、18、24 个月收取调落物袋，每次每样方每种调落叶各取 6 袋, 共计288袋。取回的调落物, 其中3袋收集后在保 温箱中冷藏，然后运回实验室放 $4{ }^{\circ} \mathrm{C}$ 冰箱保存，一 周内测调落物的酶活性。另外 3 袋挑去植物细根、泥 土及小动物等杂物(后期含泥沙较多的分解袋用清 水快速漂洗), $60{ }^{\circ} \mathrm{C}$ 烘干至恒质量, 称质量, 计算调 落物质量残留率, 然后将烘干的调落物粉碎用于测 定其化学性质。

\section{5 测定项目与方法}

将烘干后调落物样品粉碎后用碳氮元素分析仪 (Vario ELIII, Elementar, Hanau, Germany)测定调落 叶的C、N含量。调落叶P含量采用 $\mathrm{HClO}_{4}-\mathrm{H}_{2} \mathrm{SO}_{4}$ 消 煮法, 取上清液后使用连续流动分析仪 $(\mathrm{San}++$, Skalar, Breda, Netherlands)测定。用近似系统分析法 测定纤维素和木质素含量 (Ryan et al., 1990; Hendricks et al., 2000)。

参照Saiya-Cork等(2002)和Sinsabaugh等(1992) 的研究方法测定调落叶中 6 种参与分解碳氮磷循 环的胞外酶活性。用伞形酮(MUB)作为标示底物 来测定 4 类水解酶活性：包括 $\beta$-葡萄糖苷酶 $(\beta G)$ $(\mathrm{EC} 3.2 .1 .21) 、$ 纤维素水解酶 $(\mathrm{CBH})(\mathrm{EC} 3.2 .1 .91) 、 \beta-\mathrm{N}-$ 乙酰氨基葡萄糖苷酶(NAG)(EC3.1.1.14)和酸性磷 酸酶( $\mathrm{AP})(\mathrm{EC}$ 3.1.3.2)。 $\beta \mathrm{G}$ 和 $\mathrm{CBH}$ 是参与分解纤维素 的酶, $\beta \mathrm{G}$ 水解纤维二糖和其他水溶性的纤维糊精, $\mathrm{CBH}$ 作用于纤维素多糖链的末端, 释放聚糖。N获 取酶NAG主要水解含 N高分子有机物一几几丁质 (Zhou et al., 2013)。P获取酶AP在酸性条件下催化有 机磷酸单酯, 水解生成无机磷酸, 其活性的高低影 响土壤有机磷的矿化(关松荫等, 1986)。氧化酶中酚 氧化酶 $(\mathrm{PHO})(\mathrm{EC} 1.10 .3 .2)$ 和过氧化物酶( $\mathrm{PEO})(\mathrm{EC}$ 1.11.1.7) 是木质素降解酶, $\mathrm{PHO}$ 参与木质素的降解 和酚类物质的氧化, PEO可以氧化 $\mathrm{H}_{2} \mathrm{O}_{2}$, 也可以将 酚类、胺类等物质氧化为醌, 加速土壤有机物的分 解和腐殖质的合成(胡嵩等, 2013), 采用 L-二羟苯丙 氨酸(DOPA)为底物测定。用Synergy $\mathrm{H}_{4}$ 多功能酶标 仪(Molecular Devices, San Jose, USA)测定它们的荧 光度(水解酶)或吸光度(氧化酶)。

\section{6 数据处理}

各分解阶段调落叶质量残留率 $(M R)$ 计算方 法为:

$$
M R=X_{t} / X_{0} \times 100 \%
$$

式中, $X_{t}$ 为分解 $t$ 时刻调落叶的干质量 $(\mathrm{g}), X_{0}$ 为初始 时刻调落叶的干质量(g)(洪慧滨等, 2017)。

调落叶分解速率根据 Olson 指数衰减模型 (Olson, 1963)计算:

$$
Y=a \mathrm{e}^{-k t}
$$

式中, $Y$ 为调落叶的质量残留率 $(\%) ; a$ 为拟合参数; $k$ 为年分解常数; $t$ 为分解时间(a)。

调落叶分解 $50 \%\left(T_{50 \%}\right)$ 和 $95 \%\left(T_{95 \%}\right)$ 的时间计 算方法(Olson, 1963)为:

$$
\begin{aligned}
& T_{50 \%}=-\ln (1-0.5) / \mathrm{k} \\
& T_{95 \%}=-\ln (1-0.95) / \mathrm{k}
\end{aligned}
$$

元素残留率 $(N R)$ 计算方法(涂利华等, 2012)为:

$$
N R=\left(N_{t} \times M_{t}\right) /\left(N_{0} \times M_{0}\right) \times 100 \%
$$

式中, $N_{t}$ 为 $t$ 时刻调落叶元素含量 $\left(\mathrm{mg} \cdot \mathrm{g}^{-1}\right), M_{t}$ 为 $t$ 时刻 调落叶干质量 $(\mathrm{g}), N_{0}$ 为初始元素含量 $\left(\mathrm{mg} \cdot \mathrm{g}^{-1}\right), M_{0}$ 为 初始干质量 $(\mathrm{g})$ 。

所有数据均用Microsoft Excel 2016进行处理。 用SPSS 26.0软件中的独立样本 $t$ 检验对相同树种不 同处理之间的质量残留率、分解常数 $k$ 值、化学组分 残留率以及酶活性进行差异性分析; 用单因素方差 分析和最小显著差数 $(L S D)$ 法对同一处理下不同调 落叶质量残留率和分解常数 $k$ 值进行方差分析和多 重比较 $(\alpha=0.05)$, 分解时间、调落物类型和 N添加处 理对质量损失、木质素、纤维素讲解和 $\mathrm{N}$ 释放的影 响采用三因素重复测量方差分析, 调落物类型和 $\mathrm{N}$ 添加处理对6种胞外酶累积酶活性(洪慧滨等, 2017) 的影响采用双因素方差分析, 用Pearson相关分析判 断调落物质量损失速率与累积调落物酶活性和初始 化学性质之间的相关性。用Origin 9.0作图。

\section{2 结果和分析}

\section{1 不同树种凋落叶分解速率}

如图1所示, 对照情况下中, 观光木调落叶分解 最快。在前 6 个月, 观光木调落叶质量残留率显著低 于其他调落叶; 米槠调落叶分解速率次之; 杉木和 台湾相思调落叶分解最慢且两者间没有显著差异 $(p>0.05)$ 。重复测量方差分析(表4)表明, 时间变化 显著影响 4 种树木调落叶的质量损失率 $(p<0.001)$, 且从图中可以看出, 调落叶的质量残留率随时间变 化显著减少。调落叶类型显著影响调落叶的质量损 失率 $(p<0.05)$, 调落叶类型和时间的交互效应对调 


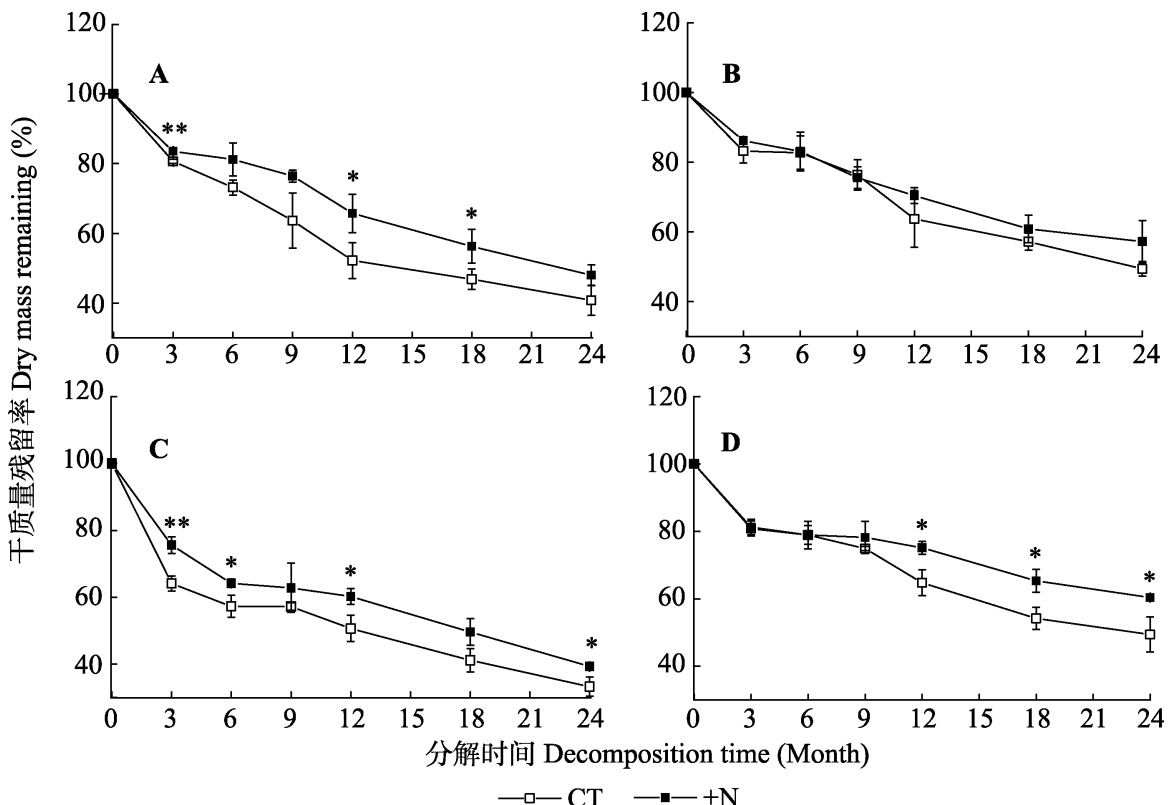

图1 亚热带森林不同处理凋落叶分解过程中质量残留率变化(平均值土标准偏差, $n=3$ )。 $\mathbf{A}$, 米槠凋落叶。 $\mathbf{B}$, 杉木凋落叶。 $\mathbf{C}$, 观光木调落叶。 $\mathbf{D}$, 台湾相思调落叶。CT, 对照; $+\mathrm{N}$, 氮添加。*,$p<0.05 ; * *, p<0.01$ 。

Fig. 1 Variations of litter mass remaining of different tree species during decomposition under different treatments in a subtropical forest (mean $\pm S D, n=3$ ). A, Castanopsis carlesii litter. B, Cunninghamia lanceolata litter. C, Michelia odora litter. D, Acacia confusa litter. $\mathrm{CT}$, control; $+\mathrm{N}$, nitrogen addition.

表3 亚热带森林不同处理凋落物分解质量残留率随时间的指数回归方程

Table 3 Exponential regression equations of mass remaining rate of leaf litter with time under different treatments in a subtropical forest

\begin{tabular}{|c|c|c|c|c|c|c|c|c|}
\hline $\begin{array}{l}\text { 树种 } \\
\text { Species }\end{array}$ & $\begin{array}{l}\text { 处理 } \\
\text { Treatment }\end{array}$ & $\begin{array}{c}\text { Olson负指数方程 } \\
\text { Olson negative } \\
\text { exponential equation }\end{array}$ & $R^{2}$ & $\begin{array}{c}\text { 分解常数 } \\
\text { Decay } \\
\text { constant } k\left(\mathrm{a}^{-1}\right)\end{array}$ & $\begin{array}{c}\text { 年实际干质量 } \\
\text { 损失率 } \\
\text { Annual observed } \\
\text { mass loss rate (\%) }\end{array}$ & $\begin{array}{c}\text { 年预期干质量 } \\
\text { 损失率 } \\
\text { Annual predicted } \\
\text { mass loss rate (\%) }\end{array}$ & $\begin{array}{c}\text { 半分解 } \\
\text { 时间 } \\
T_{50 \%} \text { (a) }\end{array}$ & $\begin{array}{c}95 \% \text { 分解 } \\
\text { 时间 } \\
T_{95 \%} \text { (a) }\end{array}$ \\
\hline 米槠 & $\mathrm{CT}$ & $Y=91.26 \mathrm{e}^{-0.440 x}$ & 0.949 & $0.440^{\mathrm{Ba}}$ & 47.794 & 42.194 & 1.292 & 5.941 \\
\hline Castanopsis carlesii & $+\mathrm{N}$ & $Y=96.35 \mathrm{e}^{-0.354 x}$ & 0.976 & $0.354^{\mathrm{Bb}}$ & 34.257 & 32.435 & 1.836 & 8.232 \\
\hline 杉木 & $\mathrm{CT}$ & $Y=95.79 \mathrm{e}^{-0.354 x}$ & 0.969 & $0.354^{\mathrm{Ca}}$ & 36.242 & 30.661 & 1.862 & 8.366 \\
\hline $\begin{array}{l}\text { Cunninghamia } \\
\text { lanceolata }\end{array}$ & $+\mathrm{N}$ & $Y=94.91 \mathrm{e}^{-0.291 x}$ & 0.968 & $0.291^{\mathrm{BCa}}$ & 29.510 & 28.215 & 2.245 & 10.167 \\
\hline 观光木 & $\mathrm{CT}$ & $Y=81.65 \mathrm{e}^{-0.557 x}$ & 0.899 & $0.557^{\mathrm{Aa}}$ & 49.333 & 38.934 & 0.993 & 5.124 \\
\hline Michelia odora & $+\mathrm{N}$ & $Y=88.03 \mathrm{e}^{-0.447 x}$ & 0.934 & $0.447^{\mathrm{Ab}}$ & 39.768 & 36.776 & 1.334 & 6.481 \\
\hline 台湾相思 & $\mathrm{CT}$ & $Y=91.26 \mathrm{e}^{-0.357 x}$ & 0.964 & $0.357^{\mathrm{Ca}}$ & 35.240 & 31.303 & 1.798 & 8.248 \\
\hline Acacia confusa & $+\mathrm{N}$ & $Y=96.35 \mathrm{e}^{-0.230 x}$ & 0.908 & $0.230^{\mathrm{Cb}}$ & 24.887 & 26.328 & 2.685 & 13.479 \\
\hline
\end{tabular}

$\mathrm{CT}$, 对照; $+\mathrm{N}$, 氮添加。不同小写字母代表同一树种不同处理之间的分解常数 $k$ 值具有显著性差异 $(p<0.05)$; 不同大写字母代表同一处理不同树种之间 的分解常数 $k$ 有显著性差异 $(p<0.05)$ 。

$\mathrm{CT}$, control; $+\mathrm{N}$, nitrogen addition. $T_{50 \%}$, half decay rate; $T_{95 \%}, 95 \%$ decay rate. Different lowercase letters denote significant differences among decay constants under different treatments in the same tree species $(p<0.05)$; different uppercase letters denote significant differences among decay constants in different tree species under the same treatment $(p<0.05)$

落叶质量损失没有影响。Olson模型拟合得到4种树 木凋落叶分解速率大小依次为观光木 $\left(0.557 \mathrm{a}^{-1}\right)$ 、米 槠 $\left(0.440 \mathrm{a}^{-1}\right)$ 、台湾相思 $\left(0.357 \mathrm{a}^{-1}\right)$ 、杉木 $\left(0.354 \mathrm{a}^{-1}\right)$, 观光木调落叶分解速率显著大于米槠调落叶，观光 木和米槠调落叶分解速率显著大于台湾相思和杉木 调落叶的分解速率 $(p<0.05)$, 台湾相思凋落叶和杉 木凋落叶分解速率无显著差异 $(p>0.05)$ (表 3 )。

\section{$2.2 \mathrm{~N}$ 添加对不同树种凋落叶分解速率的影响}

由图1可知, N添加增加了米槠和观光木调落叶 2 年分解期的质量残留率, 其中显著增加米槠调落
叶分解前中期(6-18月)的质量残留率。施 N处理显著 增加台湾相思调落叶分解中后期(9-24月)的质量残 留率。施N处理后的观光木调落叶质量残留率依然 最低, 分解最快。台湾相思调落叶在分解中后期 (9-24月)的质量残留率最高, 分解最慢。施N处理对 杉木调落叶 2 年分解过程中的质量残留率没有显著 影响 $(p>0.05)$ 。施N处理显著影响调落叶质量损失 率 $(p<0.05)$, 分解时间与施 $\mathrm{N}$ 处理, 调落物类型和 施N处理，以及 3 种因素的交互效应对调落叶质量损 失没有显著影响 $(p>0.05)$ (表 4$)$ 。 
表4 亚热带森林调落叶分解质量损失、木质素、纤维素和氮释放的三 因素重复测量方差分析

Table 4 Analysis (indicated by $F$ values from ANOVA with three factors repeated measurements) of decomposition time, litter type, nitrogen addition and their interactions on litter mass and lignin, cellulose and $\mathrm{N}$ release in a subtropical forest

\begin{tabular}{lcccr}
\hline $\begin{array}{l}\text { 差异来源 } \\
\text { Different } \\
\text { source }\end{array}$ & $\begin{array}{c}\text { 质量损失率 } \\
\text { Mass loss } \\
\text { rate }\end{array}$ & $\begin{array}{c}\text { 小质素损失率 } \\
\text { rignin loss }\end{array}$ & $\begin{array}{c}\text { 纤维素损失率 } \\
\text { Cellulose } \\
\text { loss rate }\end{array}$ & $\begin{array}{c}\text { 氮释放率 } \\
\text { N release } \\
\text { rate }\end{array}$ \\
\hline $\mathrm{T}$ & $356.428^{* * *}$ & $18920.622^{* * *}$ & $8803.023^{* * *}$ & $1266.179^{* * *}$ \\
$\mathrm{~L}$ & $60.641^{*}$ & $1798.360^{* *}$ & $4305.721^{* * *}$ & $70.640^{* *}$ \\
$\mathrm{~N}$ & $287.734^{* *}$ & $2916.781^{* * *}$ & $5176.453^{* * *}$ & $421.188^{* *}$ \\
$\mathrm{~T} \times \mathrm{L}$ & 4.114 & $1605.655^{* * *}$ & $1016.727^{* * *}$ & $14.430^{*}$ \\
$\mathrm{~T} \times \mathrm{N}$ & 2.681 & $124.624^{* *}$ & $72.162^{*}$ & $15.670^{*}$ \\
$\mathrm{~L} \times \mathrm{N}$ & 8.713 & $582.266^{* *}$ & $667.323^{* * *}$ & 7.278 \\
$\mathrm{~T} \times \mathrm{L} \times \mathrm{N}$ & 1.038 & $271.636^{* *}$ & $407.487^{* * *}$ & 2.044 \\
\hline
\end{tabular}

$\mathrm{T}$, 分解时间; $\mathrm{L}$, 调落物类型; $\mathrm{N}$, 氮添加。 $*, p<0.05 ; * *, p<0.01 ; * * *$, $p<0.001$ 。

$\mathrm{T}$, decomposition time; $\mathrm{L}$, litter type; $\mathrm{N}$, nitrogen addition.

$\mathrm{N}$ 添加处理下, Olson模型拟合 4 种调落叶分解 速率依次为观光木 $\left(0.447 \mathrm{a}^{-1}\right)$ 、米槠 $\left(0.354 \mathrm{a}^{-1}\right)$ 、杉 木 $\left(0.291 \mathrm{a}^{-1}\right)$ 、台湾相思 $\left(0.230 \mathrm{a}^{-1}\right)$, 观光木凋落叶分 解速率显著大于其他 3 种调落叶的分解速率 $(p<$ 0.05), 米槠调落叶与杉木凋落叶分解速率无显著差 异, 杉木凋落叶与台湾相思凋落叶分解速率无显著
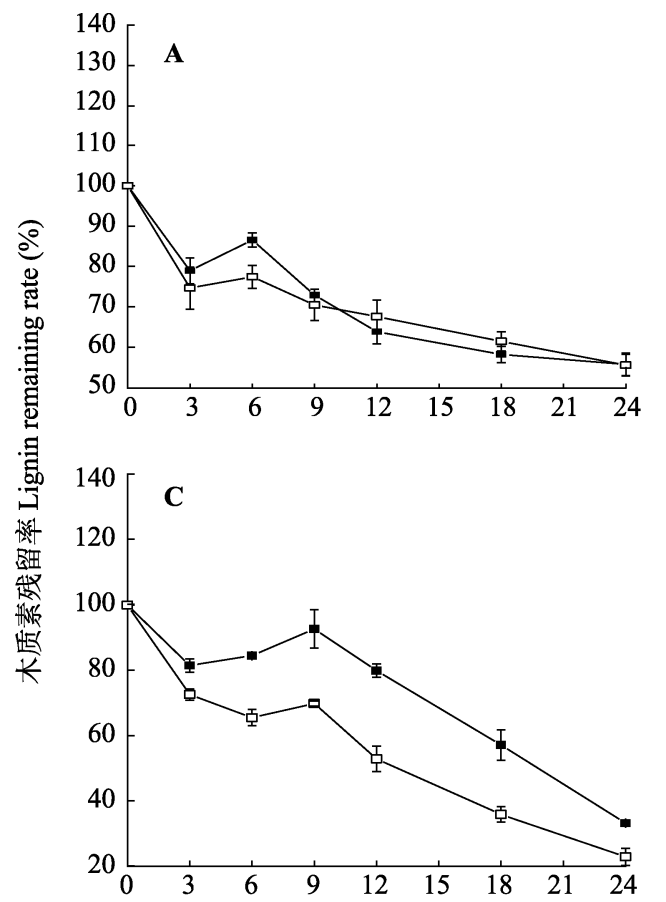

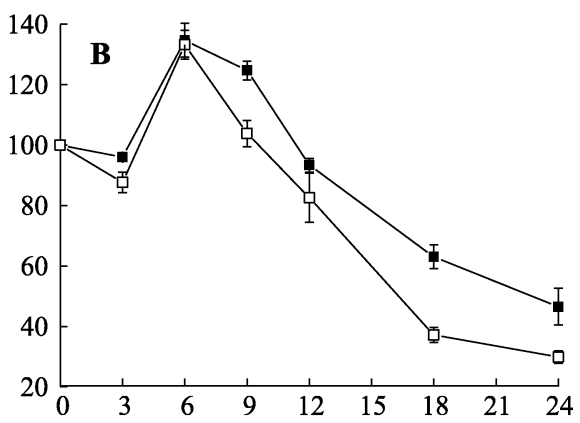

差异 $(p>0.05)$ 。与对照相比, $\mathrm{N}$ 添加后 4 个树种的调 落叶分解速率整体上都减慢，显著降低了米槠、观 光木和台湾相思调落叶的分解速率，对台湾相思调 落叶分解速率的抑制最大, 使台湾相思调落叶质量 损失 $95 \%$ 的时间在 8.248 年的基础上增加了 4.434 年 (表3)。

\section{$2.3 \mathrm{~N}$ 添加对不同树种凋落叶木质素、纤维素和氮 残留率的影响}

米槠凋落叶分解前 10 个月, $\mathrm{N}$ 添加增加木质素 残留率, 分解10-24个月木质素残留率比对照低, 实 验结束时, 施N对米槠调落叶木质素残留率没有影 响(图2A)。外源N添加增加了杉木、观光木和台湾 相思调落叶整个分解阶段的木质素残留率，分解的 中后期显著增加(图2B-2D)。三因素重复测量方差 分析表明, 分解时间、调落物类型、施 $\mathrm{N}$ 处理及其 交互作用对木质素的降解都有显著影响 $(p<0.01)$ (表4)。

米槠调落叶分解前 18 个月, $\mathrm{N}$ 添加没有显著影 响其纤维素残留率，在实验结束后，施 $\mathrm{N}$ 处理的纤 维素残留率显著高于对照(图3A)。杉木凋落叶分解

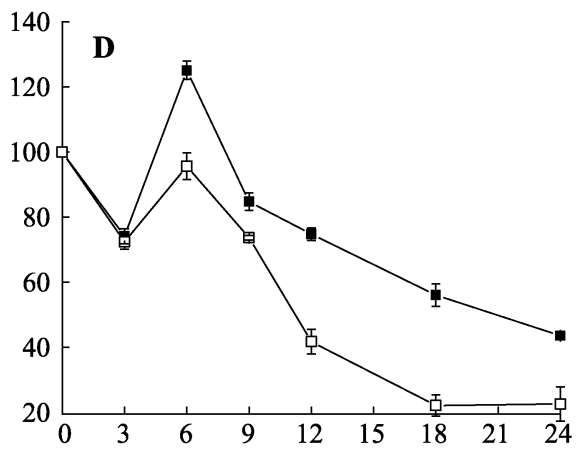

分解时间 Decomposition time (Month)

$$
-\square-\mathrm{CT}--+\mathrm{N}
$$

图2 亚热带森林不同处理凋落叶分解过程中木质素残留率变化(平均值标准偏差, $n=3$ )。 $\mathbf{A}$, 米楮凋落叶。 $\mathbf{B}$, 杉木凋落叶。 $\mathbf{C}$, 观光木凋落叶。D, 台湾相思凋落叶。CT, 对照; $+\mathrm{N}$, 氮添加。

Fig. 2 Dynamics of litter lignin remaining rates under different treatments during decomposition in a subtropical forest (mean $\pm S D, n=$ 3). A, Castanopsis carlesii litter. B, Cunninghamia lanceolata litter. C, Michelia odora litter. D, Acacia confusa litter. CT, control; +N, nitrogen addition. 


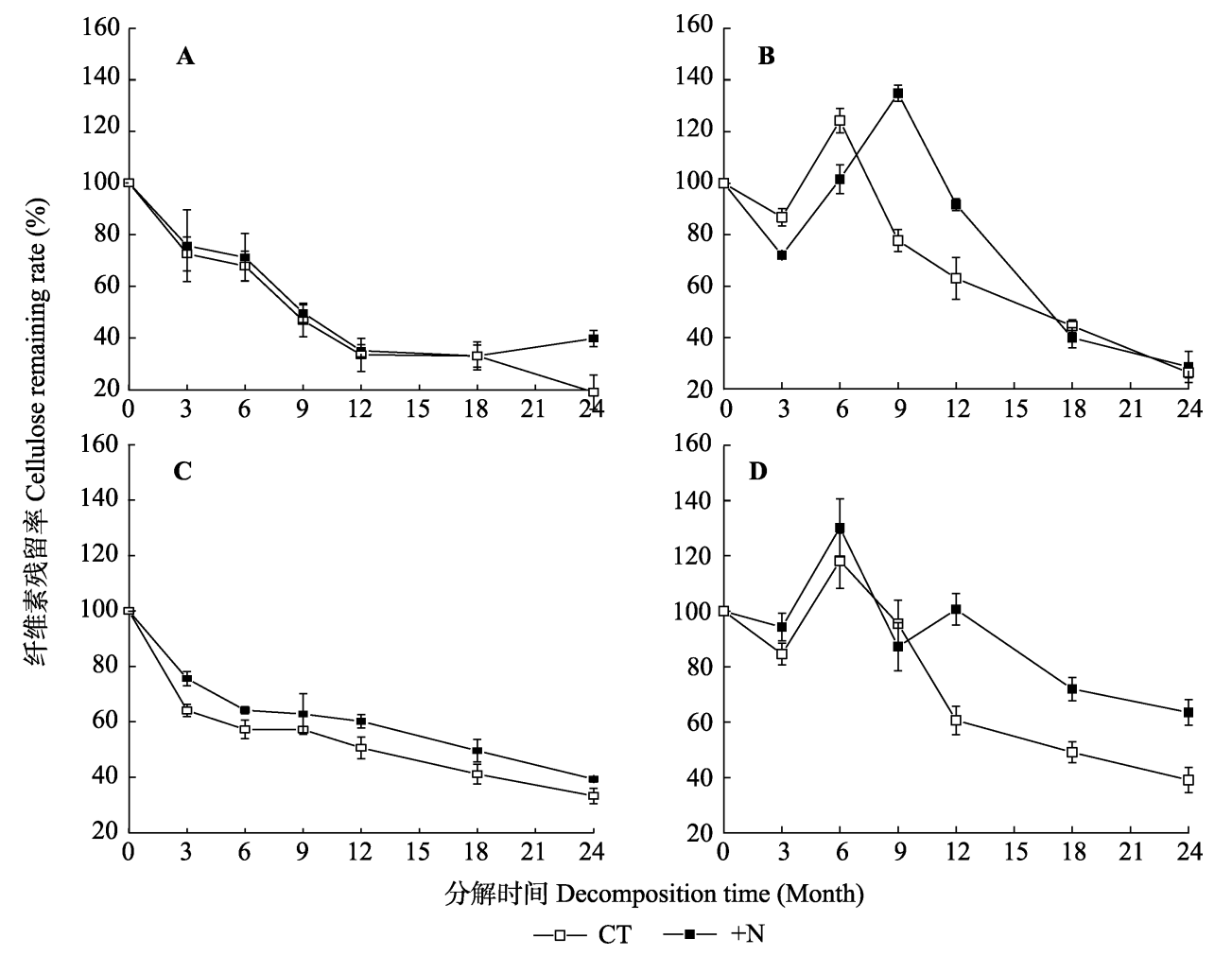

图3 亚热带森林不同处理调落叶分解过程中纤维素残留率变化(平均值土标准偏差, $n=3$ )。 $\mathbf{A}$, 米楮调落叶。 $\mathbf{B}$, 杉木凋落叶。 $\mathbf{C}$, 观光木凋落叶。D, 台湾相思凋落叶。CT, 对照; $+\mathrm{N}$, 氮添加。

Fig. 3 Dynamics of litter cellulose remaining rates under different treatments during decomposition in a subtropical forest (mean \pm $S D, n=3$ ). A, Castanopsis carlesii litter. B, Cunninghamia lanceolata litter. C, Michelia odora litter. D, Acacia confusa litter. CT, control; $+\mathrm{N}$, nitrogen addition.

前7个月, N添加减少其纤维素残留率，分解7-18个 月时，施N处理增加纤维素残留率，其中第9-12月 显著增加, 分解18-24个月, 施N处理对杉木纤维素 残留率没有明显影响(图3B)。N添加增加观光木调落 叶2年分解期的纤维素残留率(图3C), 整体增加台湾 相思调落叶纤维素残留率, 分解9个月后增加显著 (图3D)。三因素重复测量方差分析表明, 分解时间、 调落物类型、施N处理及其交互作用对纤维素的降解 都有显著影响 $(p<0.001)$ (表4), 分解时间和施N处理 的交互效应对纤维素降解的作用减弱 $(p<0.05)$ 。

米槠调落叶分解前 18 个月, $\mathrm{N}$ 添加没有显著影 响 N残留率, 18-24个月的 N残留率增加, 至实验结 束时显著高于对照(图4A)。施 $\mathrm{N}$ 处理增加了杉木调 落叶在 0-5 个月和 11-24 个月的N残留率，减少 5-11 个月的 $\mathrm{N}$ 残留率(图4B)。 N添加增加观光木调落叶2 年分解期的N残留率，增加台湾相思凋落叶9-12个 月的N残留率。三因素重复测量方差分析表明, 分解 时间、调落物类型、施 $\mathrm{N}$ 处理及分解时间分别与调 落物类型和施 $\mathrm{N}$ 处理的交互作用对 $\mathrm{N}$ 释放有显著影 响 $(p<0.01)$, 调落物类型和施 $\mathrm{N}$ 处理的交互作用,
以及调落物类型、施 $\mathrm{N}$ 处理和时间的三因素交互作 用对 $\mathrm{N}$ 释放没有影响 $(p>0.05)$ (表4)。

\section{$2.4 \mathrm{~N}$ 添加对不同树种凋落叶酶活性的影响}

由图 5 可知, $\mathrm{N}$ 添加显著提高了杉木和观光木调 落叶的 $\beta \mathrm{G}$ 活性, 对米槠和台湾相思的 $\beta \mathrm{G}$ 活性没有 影响。 $\mathrm{N}$ 添加显著提高观光木调落叶 $\mathrm{CBH}$ 活性, 却 显著抑制台湾相思凋落叶 $\mathrm{CBH}$ 活性。N添加显著降 低台湾相思凋落叶NAG的活性, 显著提高杉木调落 叶 $\mathrm{AP}$ 的活性。施 $\mathrm{N}$ 显著降低了观光木和台湾相思调 落叶的PHO活性, 却提高米槠调落叶的PEO活性外, 而对其他调落叶的过氧化物酶活性没有显著影响。 双因素方差分析结果表明，除 $\mathrm{N}$ 添加对 $\mathrm{CBH}$ 的活性 没有显著影响, 调落物类型和 $\mathrm{N}$ 添加及其交互作用 对多种胞外酶活性皆有显著效应(表5)。

\section{3 讨论}

\section{1 亚热带森林不同树种凋落叶分解速率}

不同树种通过调落叶的初始化学性质、物理性 状以及它们在生境中所处的特定条件来影响调落叶 的分解过程和分解速率(Aponte et al., 2012)。通常认 


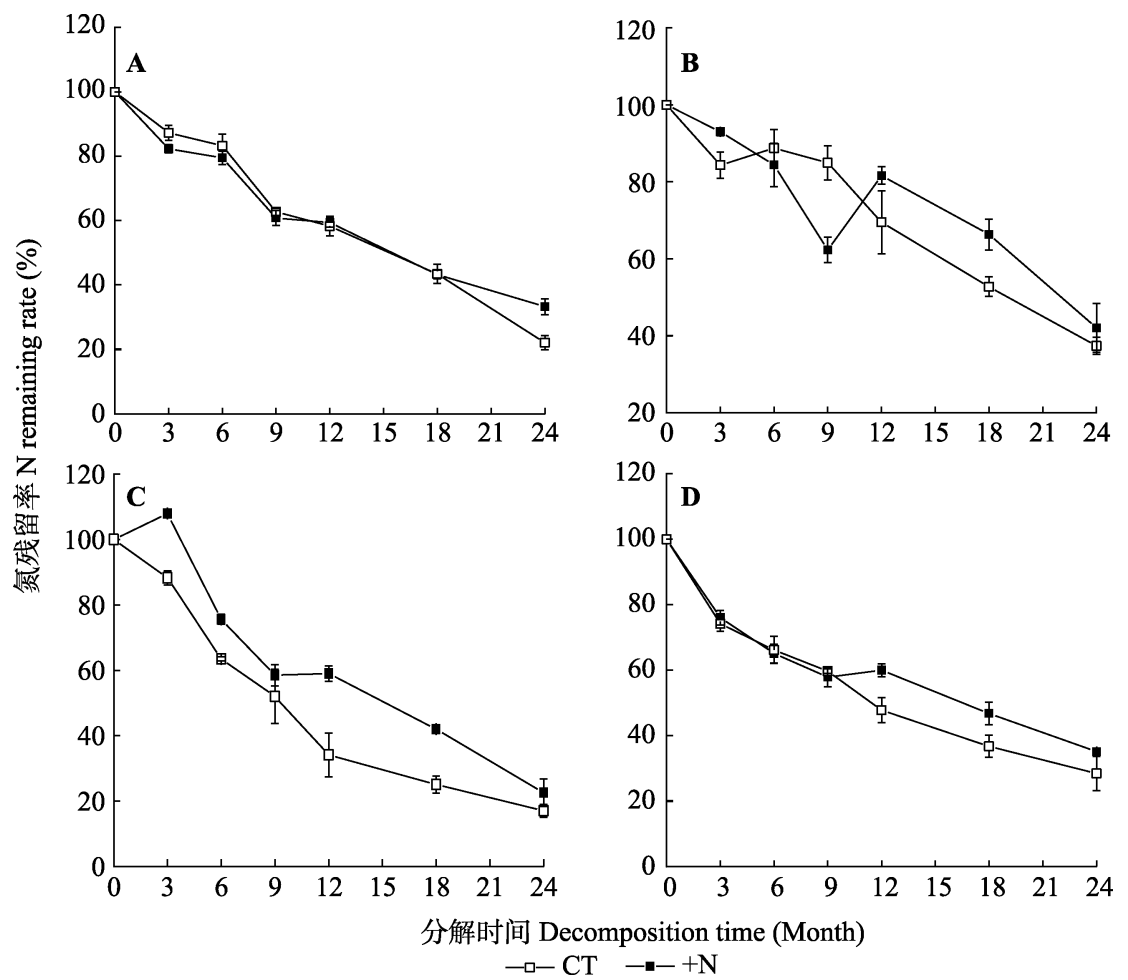

图4 亚热带森林不同处理调落叶分解过程中氮残留率变化(平均值土标准偏差, $n=3$ )。 $\mathbf{A}$, 米楮调落叶。 $\mathbf{B}$, 杉木调落叶。 $\mathbf{C}$, 观 光木淍落叶。D, 台湾相思凋落叶。CT, 对照; $+\mathrm{N}$, 氮添加。

Fig. 4 Dynamics of litter nitrogen remaining rates under different treatments during decomposition in a subtropical forest (mean \pm $S D, n=3$ ). A, Castanopsis carlesii litter. B, Cunninghamia lanceolata litter. C, Michelia odora litter. D, Acacia confusa litter. CT, control; +N, nitrogen addition.
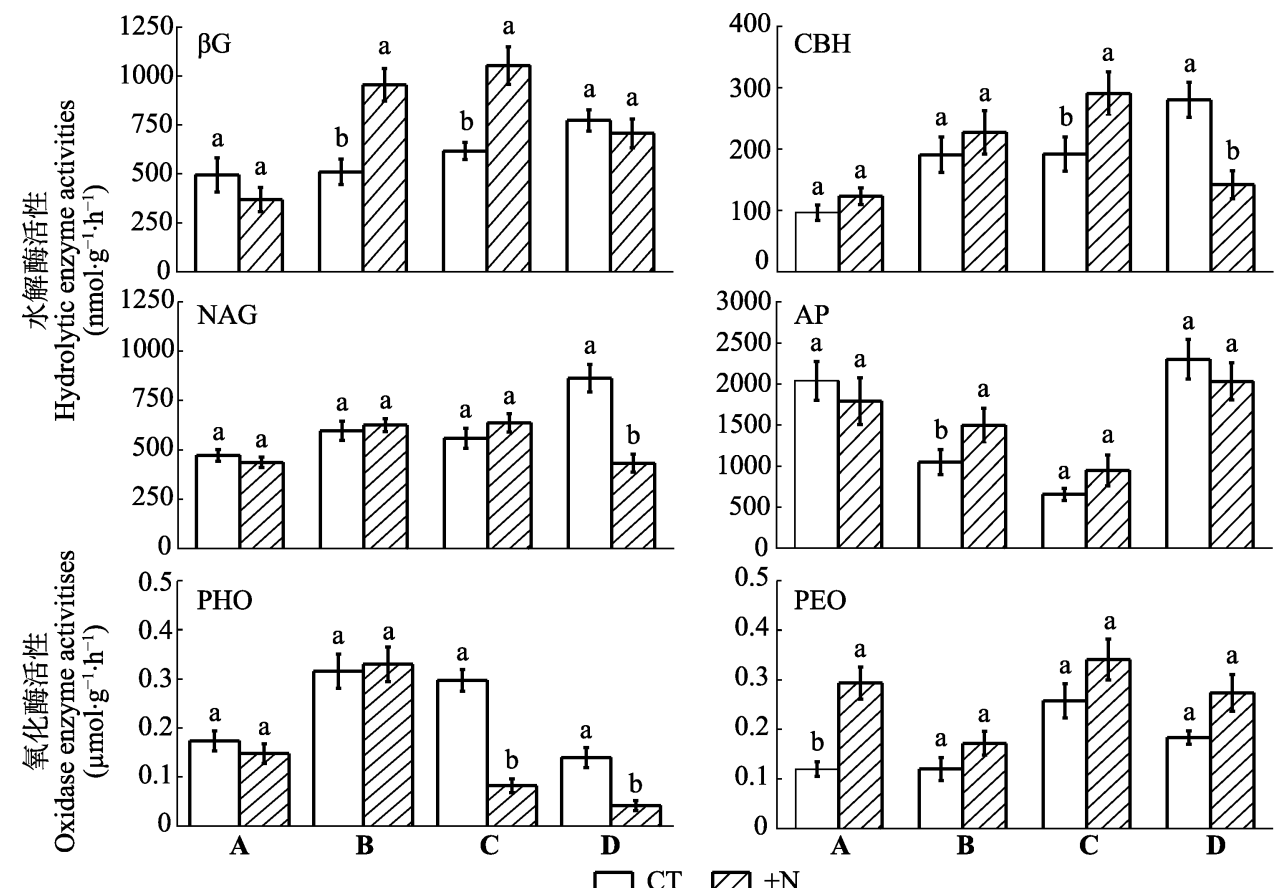

图5 亚热带森林不同处理凋落叶分解过程中平均酶活性(平均值 \pm 标准偏差, $n=3$ )。 $\mathbf{A}$, 米槠调落叶; $\mathbf{B}$, 杉木调落叶; $\mathbf{C}$, 观光木 调落叶; D, 台湾相思凋落叶。CT, 对照; $+\mathrm{N}$, 氮添加。AP, 酸性磷酸酶; $\beta \mathrm{G}, \beta$-葡萄糖苷酶; $\mathrm{CBH}$, 纤维素水解酶; $\mathrm{NAG}, \beta-\mathrm{N}-乙$ 乙酰氨 基葡萄糖苷酶; PEO, 过氧化物酶; PHO, 酚氧化酶。不同小写字母表示同一种酶活性在对照和 $\mathrm{N}$ 添加处理之间差异显著 $(p<0.05)$ 。 Fig. 5 Litter enzyme activities under different treatments during decomposition in a subtropical forest (mean $\pm S D, n=3$ ). A, Castanopsis carlesii litter; B, Cunninghamia lanceolata litter; C, Michelia odora litter; D, Acacia confusa litter. CT, control; $+\mathrm{N}$, nitrogen addition. AP, acid phosphatase; $\beta \mathrm{G}, \beta$-1,4-glucosidase; $\mathrm{CBH}$, cellobiohydrolase; NAG, $\beta$-1,4-N-acetylglucosaminidase; PEO, peroxidase; PHO, phenol oxidase. Different lowercase letters indicate significant differences among control and nitrogen addition treatments in the same enzyme $(p<0.05)$. 
表5 亚热带森林调落物酶活性的双因素方差分析

Table 5 Analysis (indicated by $F$ values from ANOVA with two factors) of litter type, nitrogen addition and their interactions on litter enzyme activity in a subtropical forest

\begin{tabular}{lcccccc}
\hline $\begin{array}{l}\text { 差异来源 } \\
\text { Different } \\
\text { source }\end{array}$ & $\beta G$ & CBH & NAG & AP & PHO & PEO \\
\hline $\mathrm{L}$ & $23.755^{* * *}$ & $35.348^{* * *}$ & $80.072^{* * *}$ & $82.374^{* * *}$ & $32.250^{* * *}$ & $97.990^{* * *}$ \\
$\mathrm{~N}$ & $27.609^{* * *}$ & 0.040 & $60.288^{* * *}$ & $7.380^{*}$ & $4.684^{*}$ & $256.223^{* * *}$ \\
$\mathrm{~L} \times \mathrm{N}$ & $21.797^{* * *}$ & $29.083^{* * *}$ & $149.790^{* * *}$ & $5.044^{*}$ & $19.714^{* * *}$ & $15.464^{* * *}$ \\
\hline
\end{tabular}

$\mathrm{L}$, 凋落物类型; $\mathrm{N}$, 氮添加。 $\mathrm{AP}$, 酸性磷酸酶; $\beta \mathrm{G}, \beta$-葡萄糖苷酶; $\mathrm{CBH}$, 纤维素水解酶; NAG, $\beta$-N-乙酰氨基葡萄糖苷酶; PEO, 过氧化物酶; $\mathrm{PHO}$, 酚氧化酶;。*, $p<0.05 ; * *, p<0.01 ; * * *, p<0.001$ 。

$\mathrm{L}$, litter type; $\mathrm{N}$, nitrogen addition. AP, acid phosphatase; $\beta \mathrm{G}, \beta$-1,4-glucosidase; $\mathrm{CBH}$, cellobiohydrolase; NAG, $\beta-1,4-\mathrm{N}$-acetylglucosaminidase; PEO, peroxidase; $\mathrm{PHO}$, phenol oxidase.

为底物养分 $(N 、 P)$ 的含量对调落叶分解前期影响较 大，而后期分解损失阶段主要与难降解的化学组分 (如木质素等)有关(Güsewell \& Gessner, 2009; Berg et al.,2010)。唐仕姗等(2014)通过建立中国调落物分 解数据库, 发现调落叶质量能解释分解常数 $k$ 值变 异的 $21.7 \%$ 。本文通过研究不同初始化学性质的4种 树木调落叶分解特征, 发现各树种调落叶分解常数 $k$ 的大小依次为观光木、米槠、台湾相思、杉木 $($ 表 $3)$, 说明调落物类型显著影响调落叶的质量损失率 $(p<0.05)$ (表4)。这与国内外的研究结果(Hirobe et al., 2004; Sariyildiz et al., 2005; Makita \& Fujii, 2015; 路 颖等, 2019)一致。本研究发现, 调落叶分解速率与 调落叶总 $\mathrm{C}$ 、木质素和纤维素含量极显著负相关 $(p<0.01)$ (表6), 这与路颖等(2019)的研究结果一 致。Sariyildiz等(2005)在土耳其东北部不同海拔和 不同坡向进行的 4 个树种调落叶分解实验也发现, 在相同的小气候下, 不同树种调落叶分解速率与调 落叶初始木质素、木质素和纤维素的组合等存在显 著相关关系, 特别是与木质素含量显著负相关。 Hirobe等(2004)在热带雨林的15种树种调落叶分解 速率和初始化学性质关系的研究中发现, 相比较其 他初始化学物质, 木质素是影响调落叶分解速率更 重要的影响因素。调落叶木质素含量与分解速率显 著负相关, 这是由于木质素属于难分解的酸不溶性
C组分, 木质素往往会在调落物分解后期积累, 因 此木质素含量高的调落物往往分解速率比较慢。

本研究发现, 调落叶分解常数 $k$ 与可萃取物极 显著正相关 $(p<0.01)$ 。可萃取物主要成分是由脂肪、 油、蜡质等组成的更易分解的非极性碳化合物以及 非结构性碳水化合物和多酚组成的极性碳化合物。 以往对调落物 $\mathrm{C}$ 组分的研究主要是木质素和纤维素 (Berg et al., 2010; 李晗等, 2015; 周世兴等, 2016a), 很少关注调落物可萃取物组分与分解速率的关系, 而初始阶段调落物质量损失主要是由于易分解的可 萃取物组分以及中度易分解的酸溶性(纤维素和半 纤维素)组分的分解(Hendricks et al., 2000)。Allison 和Vitousek (2004)研究了夏威夷来自蕨类植物和单 子叶植物茎调落物、蕨类植物调落叶以及被子植物 调落叶的 15 种类型调落物的分解发现，调落物分解 速率与高度易分解的水溶性 $\mathrm{C}$ 组分有很强的相关关 系, 其中水溶性 $\mathrm{C}$ 组分主要是酚类物质。酚类物质能 够抑制微生物降解调落物, 当酚类物质被快速淋溶 时, 调落物的分解速率就会大大加快。Melillo等 (1982)和Berg (2000)研究发现, 相对于常用的木质 素和 $\mathrm{N}$ 含量指标, 水溶性 $\mathrm{C}$ 组分更能决定调落物的 分解速率。本研究中, 自然状态下不同初始化学性 质树种的调落叶分解速率没有表现出常见的与初始 $\mathrm{N}$ 含量正相关，而是与 $\mathrm{C}$ 组分有很强的相关关系，说 明调落叶化学组分相比其初始 $\mathrm{N}$ 含量可能是更好的 预测调落叶分解速率的指标。本研究调落叶分解速 率没有与初始 $\mathrm{N}$ 含量有显著相关关系, 很可能是由 于亚热带土壤和调落叶 $\mathrm{N}$ 有效性高, $\mathrm{N}$ 不是此地区调 落叶分解的限制因子。

微生物通过分泌多种胞外酶来获得自身生长所 需要的物质, 很多研究发现胞外酶的活性可以用来 指征调落物的分解速率(Waring, 2013; Dong et al., 2019)。本研究也发现分解速率与C获取酶 $\beta G$ 有显著 相关关系，但与其他 5 种胞外酶没有显著相关关系 $(p>0.05$, 表6)。这与Waring (2013)的研究结果, C

表6 亚热带森林对照样地凋落物质量损失速率与累积酶活性和初始化学性质的Pearson相关分析 $(n=12$, 使用平均值)

Table 6 Pearson correlation coefficients $(r)$ for litter mass loss rate versus cumulative enzyme activity and initial chemistry in the control plots after 2-year decomposition in a subtropical forest $(n=12$, mean value used)

\begin{tabular}{|c|c|c|c|c|c|c|c|c|c|c|}
\hline \multicolumn{8}{|c|}{ 酶活性 Enzyme activity } & \multicolumn{3}{|c|}{ 初始性质 Initial chemistry } \\
\hline AP & $\beta G$ & $\mathrm{CBH}$ & NAG & PEO & $\mathrm{PHO}$ & $\mathrm{C}$ & $\mathrm{N}$ & 可萃取物 Extractive (\%) & 纤维素 Cellulose (\%) & 木质素 Lignin (\%) \\
\hline-1.98 & $0.661^{*}$ & 0.511 & 0.372 & 0.297 & 0.533 & $-0.817^{* *}$ & -0.530 & $0.871^{* *}$ & $-0.724^{* *}$ & $-0.848^{* *}$ \\
\hline
\end{tabular}

$\mathrm{AP}$, 酸性磷酸酶; $\beta \mathrm{G}, \beta$-葡萄糖苷酶; $\mathrm{CBH}$, 纤维素水解酶; $\mathrm{NAG}, \beta-\mathrm{N}-$ 乙酰氨基葡萄糖苷酶; PEO, 过氧化物酶; PHO, 酚氧化酶。*,$p<0.05 ; * *, p<0.01$ 。 $\mathrm{AP}$, acid phosphatase; $\beta \mathrm{G}, \beta$-1,4-glucosidase; $\mathrm{CBH}$, cellobiohydrolase; NAG, $\beta$-1,4-N-acetylglucosaminidase; $\mathrm{PEO}$, peroxidase; $\mathrm{PHO}$, phenol oxidase. *, $p<0.05 ; * *, p<0.01$.

www.plant-ecology.com 
获取酶和 $\mathrm{N}$ 获取酶与调落叶分解速率都具有显著正 相关关系相似。张瑞清等(2008)和宋影等(2014)对热 带和亚热带森林凋落物分解酶活性的研究也发现, 纤维素分解酶与调落物分解速率显著正相关。C获 取酶 $(\beta \mathrm{G}$ 和 $\mathrm{CBH})$ 是主要的纤维素分解酶, 在调落物 分解的前中期对中度易分解的纤维素分解起着重要 的作用。其中 $\beta$ G水解纤维二糖和其他水溶性的纤维 糊精, 释放出葡萄糖和相应的配基, 其活性在很大 程度上影响纤维素水解的速度, 是主要的碳获取酶 之一(Zhou et al., 2013)。调落物分解是初始化学性 质和周围环境因子交互作用下的复杂连续过程, 揭 示多种酶活性和分解的内在关系尚需更多生态系统 的研究。

\section{$3.2 \mathrm{~N}$ 添加对不同树种凋落叶分解速率的影响}

本研究发现N添加均在不同程度上增加了调落 叶的质量残留率, 这与涂利华等(2012)和周世兴等 (2016b)在华西雨屏区模拟 N沉降的研究结果类似。

$\mathrm{N}$ 添加对不同调落叶抑制作用的大小和阶段不同, 显著抑制了观光木、米槠和台湾相思凋落叶的分解 速率, 对杉木凋落叶的分解速率没有显著影响(图1; 表3), 总体表现为施 $\mathrm{N}$ 处理对 4 种调落叶分解前期 (1-3月)没有影响，而显著抑制后期的分解(图1)。这 与涂利华等(2012) 发现施 $\mathrm{N}$ 处理后期对亮叶桦 (Betula luminifera)调落叶的抑制作用显著加强的结 果相似, 可能与后期木质素的大量积累有关。本研 究中N添加抑制低木质素含量的观光木和米槠调落 叶分解, 其中对低 $\mathrm{N}$ 的米槠调落叶分解前期抑制较 强。这基本符合Knorr等(2005)的全球模拟 N沉降对 调落叶分解影响研究发现的规律, 即 $\mathrm{N}$ 添加总体上 会抑制低N或高木质素调落物的分解, 而促进高 $\mathrm{N}$ 或低木质素调落物的分解。

本研究中, 调落叶分解速率与木质素、纤维素 含量显著负相关(表6), 且多因素方差分析也证实调 落物类型和 $\mathrm{N}$ 添加的交互作用显著影响纤维素和木 质素的降解速率(表4)。因此, N沉降可能通过影响木 质素和纤维素降解, 从而导致凋落叶分解速率减 慢。 $\mathrm{N}$ 沉降抑制木质素、纤维素分解的原因可能是 施 $\mathrm{N}$ 造成的酸性条件促使铵和硝酸盐与残留木质素 及其分解产物——酚类物质发生反应, 并由多种反 应产物形成高度聚合的抗分解物质, 构成一种化学 壁垒(Hirobe et al., 2004)。而纤维素往往由木质素聚 合体包裹着(周世兴等, 2016a), 木质素分解受到抑
制，导致纤维素分解也受到抑制。

在室内和野外实验中, N添加往往会抑制微生 物活性(Ramirez et al., 2010), 当施 $\mathrm{N}$ 量超过植物对 $\mathrm{N}$ 的需求时, 会促使硝化作用的发生, 导致土壤酸化 (Gundersen \& Rasmussen, 1990)。一项全球meta分析 表明, N添加导致生态系统土壤 $\mathrm{pH}$ 约下降0.25 (Tian \& Niu, 2015)。我们先前的研究也发现模拟N沉降显 著降低了米槠天然林土壤的pH (黄锦铌等, 2017)。 土壤pH对微生物群落组成(Lauber et al., 2009)和活 性(Chen et al., 2016)具有强的负向作用, 因此N添加 会减缓微生物的生长及其分解能力(Averill \& Waring, 2018), 这可能是导致本研究4个树种的调落叶 分解速率减慢的原因。微生物通过产生胞外酶催化 调落物分解, 酶活性的变化是解释调落物分解差异 的一个重要参数(Waring, 2013; Dong et al., 2019)。 Waring (2013)对热带森林调落物层酶活性与调落物 分解常数关系的研究发现, 调落物酶活性可以解释 调落物种间分解差异的 $35 \%$ 。C arreiro等(2000)和 Sinsabaugh等(2002)研究发现PHO活性与质量损失 速率密切相关, N沉降显著降低了高木质素的橡树 调落叶中PHO活性(Carreiro et al., 2000)。本研究也 发现N添加显著抑制了高木质素的台湾相思和观光 木调落叶 $\mathrm{PHO}$ 活性, 却未显著抑制杉木调落叶 $\mathrm{PHO}$ 活性, 可能是由于调落物类型对酶活性总体水平的 影响(Waring, 2013)。台湾相思是一种固 $\mathrm{N}$ 植物, 其凋 落叶中的高 $\mathrm{N}$ 含量能满足微生物分解的需要, 添加 $\mathrm{N}$ 可能超过微生物对 $\mathrm{N}$ 的需求, 从而使台湾相思凋 落叶N获取酶NAG活性显著下降。N添加也显著抑 制了台湾相思调落叶的CBH活性(图5), 这或许是台 湾相思凋落叶中纤维素和木质素的降解速率被外源 $\mathrm{N}$ 显著抑制。N添加显著降低米楮调落叶的分解速率, 可能与其降解纤维素的水解酶 $\beta \mathrm{G}$ 以及 $\mathrm{AP}$ 和 $\mathrm{PHO}$ 活 性皆受到抑制有关。施 $\mathrm{N}$ 没有显著降低杉木凋落叶 的分解速率可能与 $\mathrm{N}$ 添加后没有降低其酶活性有关 (图5)。本研究中双因素方差分析表明, 调落物类型 和 $\mathrm{N}$ 添加以及其交互作用都对酶活性具有显著效应 (表5), 说明胞外酶活性显著影响了调落物的分解; 而PHO活性总体受到抑制(图5), 说明其是调落物分 解下降的可能原因。虽然微生物酶活性对调落物分 解速率的反应具有一定的普遍性, 但其潜在机制尚 不清楚。本研究中不同树种调落叶水解酶活性对外 源 $\mathrm{N}$ 添加的响应没有明显一致的规律, 因此对特定 
调落物或生态系统酶活性大小甚至响应方向的预测 还需要未来基于更多树种更长时间的研究。

\section{4 结论}

亚热带不同初始化学性质的 4 个树种凋落叶分 解速率差异显著。N添加总体抑制了亚热带 4 个树种 调落叶的分解速率, 减缓调落叶 $\mathrm{N}$ 释放, 对调落叶 分解速率的抑制作用主要通过减缓纤维素和木质素 降解。两年的分解实验表明, 调落叶自身的 $\mathrm{N}$ 含量并 不是调控亚热带森林调落叶分解速率的主导因素, 而其化学组分在很大程度上决定凋落物的分解速 率。胞外酶活性大小能反应不同凋落物的分解速率, 然而 N添加情况下水解酶活性的变化未表现一致的 规律。这种现象需要未来包括更多调落物进行更深 入的研究加以解释。

\section{参考文献}

Aerts R (1997). Climate, leaf litter chemistry and leaf litter decomposition in terrestrial ecosystems: a triangular relationship. Oikos, 79, 439-449.

Allison SD, Vitousek PM (2004). Extracellular enzyme activities and carbon chemistry as drivers of tropical plant litter decomposition. Biotropica, 36, 285-296.

Aponte C, García LV, Maranón T (2012). Tree species effect on litter decomposition and nutrient release in Mediterranean oak forests changes over time. Ecosystems, 15, 1204-1218.

Averill C, Waring B (2018). Nitrogen limitation of decomposition and decay: How can it occur? Global Change Biology, 24, 1417-1427.

Berg B (2000). Litter decomposition and organic matter turnover in northern forest soils. Forest Ecology and Management, 133, 13-22.

Berg B, Davey MP, de Marco A, Emmett B, Faituri M, Hobbie SE, Johansson MB, Liu C, McClaugherty C, Norell L, Rutigliano FA, Vesterdal L, de Santo AV (2010). Factors influencing limit values for pine needle litter decomposition: a synthesis for boreal and temperate pine forest systems. Biogeochemistry, 100, 57-73.

Carreiro MM, Sinsabaugh RL, Repert DA, Parkhurst DF (2000). Microbial enzyme shifts explain litter decay responses to simulated nitrogen deposition. Ecology, 81, 2359-2365.

Chen DM, Li JJ, Lan ZC, Hu SJ, Bai YF (2016). Soil acidification exerts a greater control on soil respiration than soil nitrogen availability in grasslands subjected to long-term nitrogen enrichment. Functional Ecology, 30, 658-669.

Chen ZF, Chen TQ, Huang WY (2016). Researches on soil physical properties of Acacia water conservation forest. Anhui Agricultural Science Bulletin, 22, 122-123. [陈志 锋, 陈统泉, 黄伟毅 (2016). 台湾相思水源涵养林土壤 物理性质研究. 安徽农学通报, 22, 122-123.]

Cornwell WK, Cornelissen JHC, Kathryn A, Ellen D, Eviner VT, Oscar G, Hobbie SE, Bart H, Hiroko K, Natalia PH (2008). Plant species traits are the predominant control on litter decomposition rates within biomes worldwide. Ecology letters, 11, 1065-1071.

Cotrufo MF, Wallenstein MD, Boot CM, Denef K, Paul E (2013). The Microbial Efficiency-Matrix Stabilization (MEMS) framework integrates plant litter decomposition with soil organic matter stabilization: Do labile plant inputs form stable soil organic matter? Global Change Biology, 19, 988-995.

Dong LL, Sun T, Berg B, Zhang LL, Zhang QQ, Wang ZW (2019). Effects of different forms of $\mathrm{N}$ deposition on leaf litter decomposition and extracellular enzyme activities in a temperate grassland. Soil Biology \& Biochemistry, 134, 78-80.

Fang H, Mo JM, Peng SL, Li ZA, Wang H (2007). Cumulative effects of nitrogen additions on litter decomposition in three tropical forests in Southern China. Plant and Soil, 297, 233-242.

Galloway JN, Townsend AR, Erisman JW, Bekunda M, Cai Z, Freney JR, Martinelli LA, Seitzinger SP, Sutton MA (2008). Transformation of the nitrogen cycle: recent trends, questions, and potential solutions. Science, 320, 889-892.

Guan SY, Zhang DS, Zhang ZM (1986). Soil Enzyme and Its Research Method. Agricultural Press, Beijing. [关松荫, 张德生, 张志明 (1986). 土壤酶及其研究法. 农业出版 社, 北京.]

Gundersen P, Rasmussen L (1990). Nitrification in forest soils: effects from nitrogen deposition on soil acidification and aluminum release. Reviews of environmental contamination and toxicology, 113, 1-45.

Güsewell S, Gessner MO (2009). N:P ratios influence litter decomposition and colonization by fungi and bacteria in microcosms. Functional Ecology, 23, 211-219.

Hendricks JJ, Aber JD, Nadelhoffer KJ, Hallett RD (2000). Nitrogen controls on fine root substrate quality in temperate forest ecosystems. Ecosystems, 3, 57-69.

Hirobe M, Sabang J, Bhatta BK, Takeda H (2004). Leaf-litter decomposition of 15 tree species in a lowland tropical rain forest in Sarawak: decomposition rates and initial litter chemistry. Journal of Forest Research, 9, 341-346.

Hirobe M, Sabang J, Bhatta BK, Takeda H (2004). Leaf-litter decomposition of 15 tree species in a lowland tropical rain forest in Sarawak: decomposition rates and initial litter chemistry. Journal of Forest Research, 9, 341-346.

Hobbie SE, Eddy WC, Buyarski CR, Adair EC, Ogdahl ML,

www.plant-ecology.com 
Weisenhorn P (2012). Response of decomposing litter and its microbial community to multiple forms of nitrogen enrichment. Ecological Monographs, 82, 389-405.

Hong HB, Lin CF, Peng JQ, Chen YM, Wei CC, Yang YS (2017). Effects of phosphorus addition on fine root decomposition and enzyme activity of Castanopsis carlesii and Cunninghamia lanceolata in subtropical forest. Acta Ecologica Sinica, 37, 136-146. [洪慧滨, 林成芳, 彭建 勤, 陈岳民, 魏翠翠, 杨玉盛 (2017). 磷添加对中亚热 带米槠和杉木细根分解及其酶活性的影响. 生态学报, 37, 136-146.]

Hu S, Zhang Y, Shi RJ, Han SQ, Li H, Xu H (2013). Temporal variations of soil microbial biomass and enzyme activities during the secondary succession of primary broadleaved-Pinuskoraiensis forests in Changbai Mountains of Northeast China. Chinese Journal of Applied Ecology, 24, 366-372. [胡嵩, 张颖, 史荣久, 韩斯琴, 李慧, 徐慧 (2013). 长白山原始红松林次生演替过程中土壤微生物 生物量和酶活性变化. 应用生态学报, 24, 366-372.]

Huang JN, Cheng Y, Yang HY, Zheng KZ, Wang JJ (2017). Analysis of the dynamic soil nutrients of a Castanopsis carlesii, Chinese Chestnut \& Sightseeing Wood natural forest under simulated nitrogen deposition. Acta Ecologica Sinica, 37, 63-73. [黄锦铌, 程显, 杨红玉, 郑凯舟, 王 家骏 (2017). 模拟 $N$ 沉降下三种林分土壤营养动态分 析. 生态学报, 37, 63-73.]

Keiser AD, Keiser DA, Strickland MS, Bradford MA (2014). Disentangling the mechanisms underlying functional differences among decomposer communities. Journal of Ecology, 102, 603-609.

Knorr M, Frey SD, Curtis PS (2005). Nitrogen additions and litter decomposition: a meta-analysis. Ecology, 86, 3252-3257.

Lauber CL, Hamady M, Knight R, Fierer N (2009). Pyrosequencing-based assessment of soil $\mathrm{pH}$ as a predictor of soil bacterial community structure at the continental scale. $A p$ plied and Environmental Microbiology, 75, 5111-5120.

Li H, Wu FZ, Yang WQ, Xu LY, Ni XY, He J, Chang CH (2015). Effects of snow cover on acid-soluble extractive and acid-insoluble residue during foliar litter decomposition in the alpine forest. Acta Ecologica Sinica, 35, 4687-4698. [李晗, 吴福忠, 杨万勤, 徐李亚, 倪祥银, 何洁, 常晨晖 (2015). 不同厚度雪被对高山森林6种调 落物分解过程中酸溶性和酸不溶性组分的影响. 生态 学报, 35, 4687-4698.]

Li XF, Han SJ, Hu YL, Zhao YT (2008). Decomposition of litter organic matter and its relations to $\mathrm{C}, \mathrm{N}$ and $\mathrm{P}$ release in secondary conifer and broadleaf mixed forest in Changbai Mountains. Chinese Journal of Applied Ecology, 19, 245-251. [李雪峰, 韩士杰, 胡艳玲, 赵玉涛 (2008). 长白山次生针阔混交林叶调落物中有机物分解与碳、氮 和磷释放的关系. 应用生态学报, 19, 245-251.]
Lin CF, Peng JQ, Hong HB, Yang ZJ, Yang YS (2017). Effect of nitrogen and phosphorus availability on forest litter decomposition. Acta Ecologica Sinica, 37, 54-62. [林成芳, 彭建勤，洪慧滨，杨智杰，杨玉盛 (2017). 氮、磷养分有 效性对森林调落物分解的影响研究进展. 生态学报, 37 , 54-62.]

Lin WS, Yang ZJ, Guo JF, Huang YM, Wang JJ, Wu BB, Liu XF, Lyu LX, Chen GS (2013). Changes of soil dissolved organic carbon after converting natural Castanopsis carlesis forest into Cunninghamia lanceolata plantation in subtropical China. Journal of Subtropical Resources and Environment, 8, 41-47. [林伟盛, 杨智杰, 郭剑芬, 黄咏 梅, 王家骏, 吴波波, 刘小飞, 吕理兴, 陈光水 (2013). 米槠天然林转变成杉木人工林后土壤可溶性有机碳的 变化. 亚热带资源与环境学报, 8, 41-47.]

Lu Y, Li K, Liang Q, Li CR, Zhang CH (2019). Effects of leaf litter decomposition on bacterial community structure in the leaf litter of four dominant tree species in Mount Tai. Acta Ecologica Sinica, 39, 3175-3186. [路颖, 李坤, 梁 强, 李传荣, 张彩虹 (2019). 泰山4种优势造林树种叶 片调落物分解对调落物内细菌群落结构的影响. 生态 学报, 39, 3175-3186.]

Makita N, Fujii S (2015). Tree species effects on microbial respiration from decomposing leaf and fine root litter. Soil Biology \& Biochemistry, 88, 39-47.

Melillo JM, Aber JD, Muratore JF (1982). Nitrogen and lignin control of hardwood leaf litter decomposition dynamics. Ecology, 63, 621-626.

Olson JS (1963). Energy storage and the balance of producers and decomposers in ecological systems. Ecology, 44, 322-331.

Palozzi JE, Lindo Z (2018). Are leaf litter and microbes team players? Interpreting home-field advantage decomposition dynamics. Soil Biology \& Biochemistry, 124, 189-198.

Ramirez KS, Craine JM, Fierer N (2010). Nitrogen fertilization inhibits soil microbial respiration regardless of the form of nitrogen applied. Soil Biology \& Biochemistry, 42, 2336-2338.

Ryan MG, Melillo JM, Ricca A (1990). A comparison of methods for determining proximate carbon fractions of forest litter. Canadian Journal of Forest Research, 20, 166-171.

Saiya-Cork KR, Sinsabaugh RL, Zak DR (2002). The effects of long term nitrogen deposition on extracellular enzyme activity in an Acer saccharum forest soil. Soil Biology \& Biochemistry, 34, 1309-1315.

Sariyildiz T, Anderson JM, Kucuk M (2005). Effects of tree species and topography on soil chemistry, litter quality, and decomposition in Northeast Turkey. Soil Biology \& Biochemistry, 37, 1695-1706.

Sinsabaugh RL, Carreiro MM, Repert DA (2002). Allocation of extracellular enzymatic activity in relation to litter composition, $\mathrm{N}$ deposition, and mass loss. Biogeochemistry, 60, 
$1-24$.

Sinsabaugh RL, Gallo ME, Lauber C, Waldrop MP, Zak DR (2005). Extracellular enzyme activities and soil organic matter dynamics for northern hardwood forests receiving simulated nitrogen deposition. Biogeochemistry, 75, 201-215.

Sinsabaugh RL, Weiland T, Linkins AE (1992). Enzymic and molecular analysis of microbial communities associated with lotic particulate organic matter. Freshwater Biology, 28, 393-404.

Song Y, Gu XR, Yan HY, Mao WT, Wu XL, Wan YX (2014). Dynamics of microbes and enzyme activities during litter decomposition of Pinus massoniana forest in midsubtropical area. Environmental Science, 35, 1151-1158. [宋影, 辜夕容, 严海元, 毛文搯, 吴雪莲, 万宇轩 (2014). 中亚热带马尾松林调落物分解过程中的微生物 与酶活性动态. 环境科学, 35, 1151-1158.]

Stursova M, Crenshaw CL, Sinsabaugh RL (2006). Microbial responses to long-term $\mathrm{N}$ deposition in a semiarid grassland. Microbial Ecology, 51, 90-98.

Tang SS, Yang WQ, Yin R, Xiong L, Wang HP, Wang B, Zhang Y, Peng YJ, Chen QS, Xu ZF (2014). Spatial characteristics in decomposition rate of foliar litter and controlling factors in Chinese forest ecosystems. Chinese Journal of Plant Ecology, 38, 529-539. [唐仕姗, 杨万勤, 殷睿, 熊莉, 王海鹏, 王滨, 张艳, 彭艳君, 陈青松, 徐 振锋 (2014). 中国森林生态系统调落叶分解速率的分 布特征及其控制因子. 植物生态学报, 38, 529-539.]

Tian DS, Niu SL (2015). A global analysis of soil acidification caused by nitrogen addition. Environmental Research Letters, 10, 024019. DOI: 10.1088/1748-9326/10/2/024019.

Tu LH, Hu HL, Hu TX, Zhang J, Luo SH, Dai HZ (2012). Response of Betula luminifera leaf litter decomposition to simulated nitrogen deposition in the Rainy Area of West China. Chinese Journal of Plant Ecology, 36, 99-108. [涂 利华, 胡红玲, 胡庭兴, 张健, 雒守华, 戴洪忠 (2012). 华西雨屏区亮叶桦调落叶分解对模拟氮沉降的响应. 植物生态学报, 36, 99-108.]

van Huysen TL, Perakis SS, Harmon ME (2016). Decomposition drives convergence of forest litter nutrient stoichiometry following phosphorus addition. Plant and Soil, 406, $1-14$.

Vitousek PM, Aber JD, Howarth RW, Likens GE, Matson PA, Schindler DW, Schlesinger WH, Tilman DG (1997). Human alteration of the global nitrogen cycle: sources and consequences. Ecological Applications, 7, 737-750.

Vivanco L, Austin AT (2011). Nitrogen addition stimulates forest litter decomposition and disrupts species interactions in Patagonia, Argentina. Global Change Biology, 17, 1963-1974.

Wang JJ, Cheng Y, Yang YS, Lin CF, Lin WS, Peng JQ (2014). Responses of leaf litter decomposition and nutrient release to simulated nitrogen deposition of Castanopsis carlesii. Journal of Fujian College of Forestry, 34, 113-119. [王家骏, 程煜, 杨玉盛, 林成芳, 林伟盛, 彭 建勤 (2014). 米槠叶调落物分解及养分释放对模拟 $\mathrm{N}$ 沉 降的响应. 福建林学院学报, 34, 113-119.]

Waring BG (2013). Exploring relationships between enzyme activities and leaf litter decomposition in a wet tropical forest. Soil Biology \& Biochemistry, 64, 89-95.

Wieder WR, Cleveland CC, Townsend AR (2009). Controls over leaf litter decomposition in wet tropical forests. Ecology, 90, 3333-3341.

Yan JF, Wang L, Hu Y, Tsang YF, Zhang YN, Wu JH, Fu XH, Sun Y (2018). Plant litter composition selects different soil microbial structures and in turn drives different litter decomposition pattern and soil carbon sequestration capability. Geoderma, 319, 194-203.

Yang L, Deng CC, Chen YM, He RL, Zhang J, Liu Y (2015). Relationships between decomposition rate of leaf litter and initial quality across the alpine timberline ecotone in Western Sichuan, China. Chinese Journal of Applied Ecology，26，3602-3610. [杨林, 邓长春, 陈亚梅, 和润 莲, 张健, 刘洋 (2015). 川西高山林线交错带调落叶分 解速率与初始质量的关系。应用生态学报, 26 , 3602-3610.]

Yang YS, Guo JF, Chen GS, Yin YF, Gao R, Lin CF (2009). Effects of forest conversion on soil labile organic carbon fractions and aggregate stability in subtropical China. Plant and Soil, 323, 153-162.

Yu Q, Duan L, Yu LF, Chen X, Si GY, Ke PP, Ye ZX, Mulder J (2018). Threshold and multiple indicators for nitrogen saturation in subtropical forests. Environmental Pollution, 241, 664-673.

Zhang RQ, Sun ZJ, Wang C, Yuan TY (2008). Ecological process of leaf litter decomposition in tropical rainforest in Xishuangbanna, SW China. III. Enzyme dynamics. Journal of Plant Ecology (Chinese Version), 32, 622-631. [张 瑞清, 孙振钧, 王冲, 袁堂玉 (2008). 西双版纳热带雨 林调落叶分解的生态过程. III. 酶活性动态. 植物生态 学报, 32, 622-631.]

Zhang XY, Wang W (2015). Control of climate and litter quality on leaf litter decomposition in different climatic zones. Journal of Plant Research, 128, 791-802.

Zheng JQ, Guo RH, Li DS, Zhang JH, Han SJ (2017). Nitrogen addition, drought and mixture effects on litter decomposition and nitrogen immobilization in a temperate forest. Plant and Soil, 416, 165-179.

Zheng YX, Cao JL, Yang ZJ, Lin CF, Yang YS (2018). Impacts of nitrogen deposition on soil microbial community structure in subtropical natural evergreen broad-leaved forest relative to season. Acta Pedologica Sinica, 55, 1534-1544. [郑裕雄, 曹际玲, 杨智杰, 林成芳, 杨玉盛 (2018). 氮 沉降对亚热带常绿阔叶天然林不同季节土壤微生物群

www.plant-ecology.com 
落结构的影响. 土壤学报, 55, 1534-1544.]

Zhou SX, Huang CD, Xiang YB, Han BH, Xiao YX, Tang JD (2016a). Effects of simulated nitrogen deposition on lignin and cellulose degradation of foliar litter in natural evergreen broad-leaved forest in Rainy Area of Western China. Chinese Journal of Applied Ecology, 27, 1368-1374. [周 世兴, 黄从德, 向元涁, 韩博涵, 肖永翔, 唐剑东 (2016a). 模拟氮沉降对华西雨屏区天然常绿阔叶林调 落物木质素和纤维素降解的影响. 应用生态学报, 27 , 1368-1374.]

Zhou SX, Xiao YX, Xiang YB, Huang CD, Tang JD, Han BH, Luo C (2016b). Effects of simulated nitrogen deposition on the substrate quality of foliar litter in a natural evergreen broad-leaved forest in the Rainy Area of Western China. Acta Ecologica Sinica, 36, 7428-7435. [周世兴,
肖永翔, 向元涁, 黄从德, 唐剑东, 韩博涵, 罗超 (2016b). 模拟氮沉降对华西雨屏区天然常绿阔叶林调 落叶分解过程中基质质量的影响. 生态学报, 36 , 7428-7435.]

Zhou XQ, Chen CR, Wang YF, Xu ZH, Han HY, Li LH, Wan SQ (2013). Warming and increased precipitation have differential effects on soil extracellular enzyme activities in a temperate grassland. Science of The Total Environment, 444, 552-558.

Zhou ZH, Wang CK, Zheng MH, Jiang LF, Luo YQ (2017). Patterns and mechanisms of responses by soil microbial communities to nitrogen addition. Soil Biology \& Biochemistry, 115, 433-441.

特邀编委: 白文明 编辑: 赵 航 